\title{
A review of flow acoustic effects on a commercial automotive exhaust system - methods and materials
}

Barhm MOHAMAD

DOI: 10.30464/jmee.2019.3.2.149

Cite this article as:

Mohamad B. A review of flow acoustic effects on a commercial automotive exhaust system - methods and materials. Journal of Mechanical and Energy Engineering, Vol. 3(43), No. 2, 2019, pp. 149-156.

\section{VOLUME 3(43) | No. 2 | JUNE 2019}

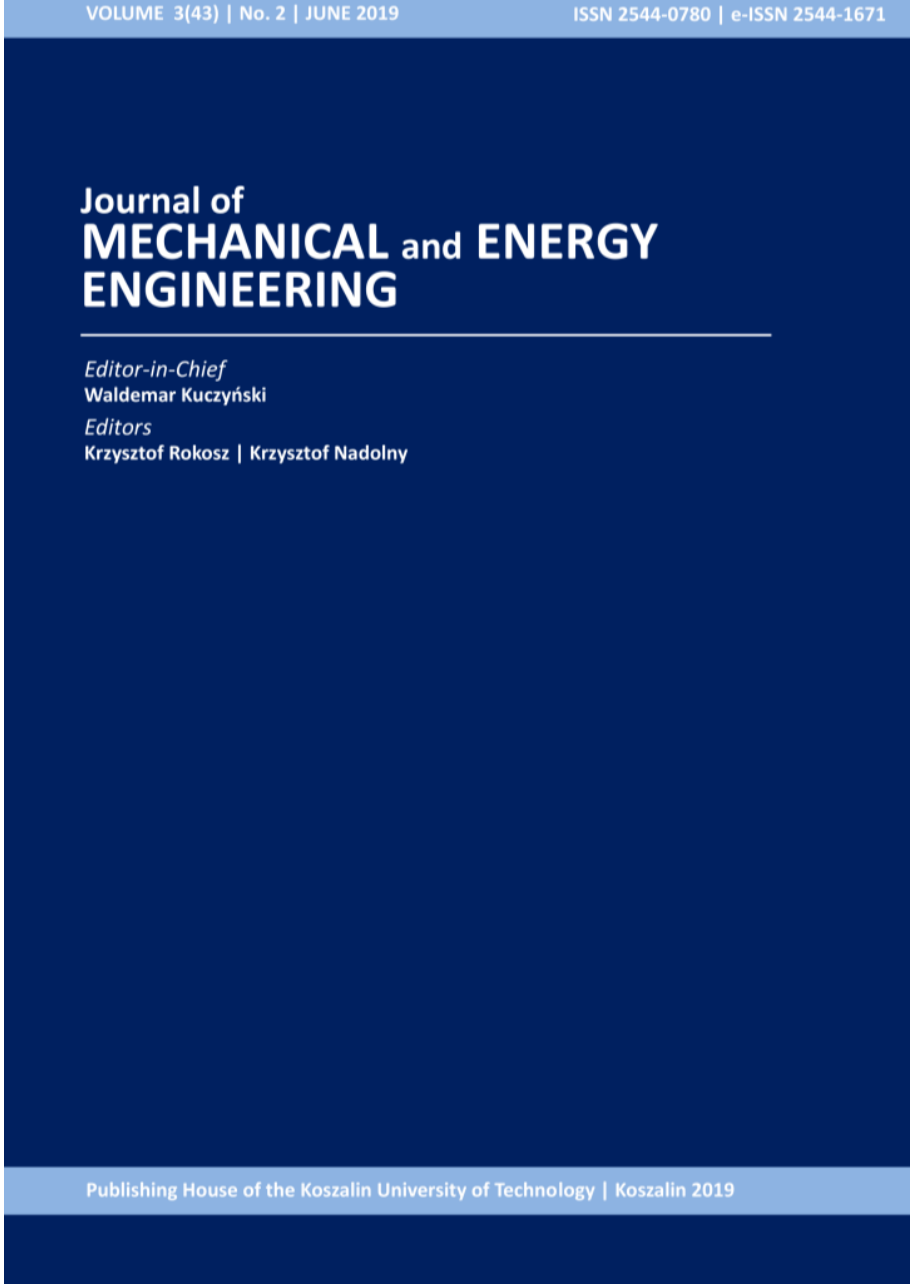

Journal of Mechanical and Energy Engineering

Website: jmee.tu.koszalin.pl

ISSN (Print): 2544-0780

ISSN (Online): 2544-1671

Volume: 3(43)

Number: 2

Year: 2019

Pages: 149-156

Article Info:

Received 8 April 2019

Accepted 13 May 2019

\section{Open Access}

This article is distributed under the terms of the Creative Commons Attribution 4.0 (CC BY 4.0) International License (http://creativecommons.org/licenses/by/4.0/), which permits unrestricted use, distribution, and reproduction in any medium, provided you give appropriate credit to the original author(s) and the source, provide a link to the Creative Commons license, and indicate if changes were made. 


\title{
A REVIEW OF FLOW ACOUSTIC EFFECTS ON A COMMERCIAL AUTOMOTIVE EXHAUST SYSTEM - METHODS AND MATERIALS
}

\author{
Barhm MOHAMAD $^{1 *}$ \\ ${ }^{1 *}$ Faculty of Mechanical Engineering and Informatics, University of Miskolc, 3515 Miskolc, Hungary \\ e-mail: pywand@gmail.com
}

(Received 8 April 2019, Accepted 13 May 2019)

\begin{abstract}
Literature review on flow acoustic methods and materials of an automotive muffler. a car is judged comfortable also depending on the acoustic level transmitted inside, and a thorough knowledge of acoustics of ducts and mufflers is needed for the design of efficient muffler configurations. Unstable exhaust gas at high temperature flowing from internal combustion engine manifold may cause of noise and vibrations conflicting with the high standard of acoustic comfort requested by this kind of vehicle. The basic gaols are to define most important methods to identify noise occur from the motion of fluid in case of turbulent model. Materials properties like velocity, temperature, thermal conductivity and density have been technical presented in this work.
\end{abstract}

Keywords: Internal combustion engine, Exhaust gas system, Two-source method, Two-load method, Acoustic analysis, Computational Fluid Dynamic

\section{INTRODUCTION}

Though the prime function of muffler is to reduce engine noise, it is designed to control the back pressure of the exhaust system as well. Performance of an engine greatly depends on the effective exhaust of the combustion gases and its properties to atmosphere through muffler. The variation back pressure has the direct effect on muffler temperature distribution that regulates fuel economy, wave propagation and energy loss.

\section{LITERATURE REWIEV}

Prakash Chandra Mishra et al. Studied the effect of muffler geometry modification on exhaust parameters of an engine. Such engine is powered with blend of methanol and gasoline by different volume percentage blended with $95 \%$ petrol, $5 \%$ methanol; $90 \%$ petrol, $10 \%$ methanol and $85 \%$ petrol, $15 \%$ methanol blends respectively. Based on heat release from combustion of different type of fuels, has direct effects on exhaust gas properties. In this research four type of geometry chambered straight (CS), chambered elliptic (CE), turbo straight (TS) and turbo elliptic (TE) was used to identify acoustic level. The author also shows the relation between emission and gas cooling through a muffler. The result from CFD analysis was show the exhaust gases from inlet pipe passes through the baffle or perforated pipe inside the shell, the gases get scattered in different directions. The variation of pressure, velocity, temperature distribution, and flow were calculated. After reflection from the wall, the cancellation of sound waves occurs. Such process occurs multiple times resulted in reduction of sound with in muffler. K. Ashok Reddy made a survey on optimization of automotive muffler. This review depicts about transmission loss characteristics, different methods used in the design, calculation and construction of reactive and reflective mufflers both experimentally and in practical. Prakash Chandra Mishra at al. studied the effect of perforated and nonperforated muffler on outlet temperature. A computational fluid dynamic method was used to develop muffler performance. Based on the solver, the effect of back pressure, temperature, density and velocity streamline of exhaust gas on the muffler performance was studied for different blends $(5 \%$, $10 \%, 15 \%$ ) of gasoline and methanol by volume percentage. 


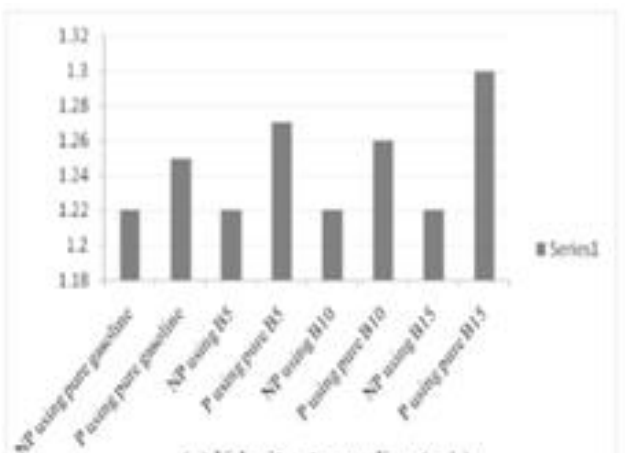

(a) Velocity stream line (mis)

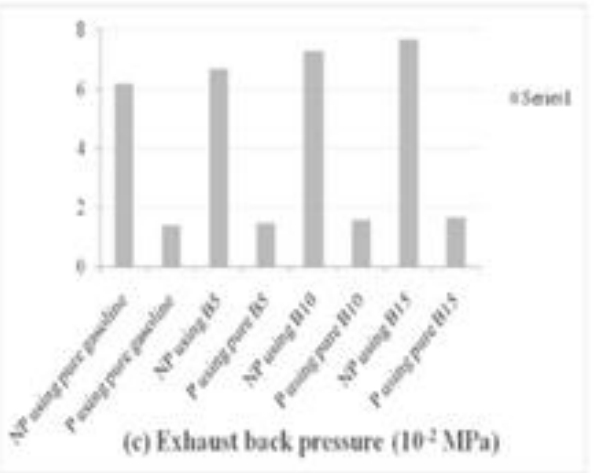

Fig. 1. Bar chart for comparative analysis [Prakash et al, 2018]

Result show clear variations of these parameters are observed between non-perforated and perforated type turbo pipe mufflers. In Figure 1 result of CFD analysis for different design parameter and fuels.

M.L. Munjal et al. presented in their research paper the effects of reverse flow in three duct, openend perforated element muffler, by using transfer matrix method to predict noise reduction through system. The result was validated with experimental data using two-load method as shows in Figure 2.

M.L. Munjal, studied transmission loss [TL] for a muffler system, transfer matrix method has been derived for side inlet and side outlet elements for
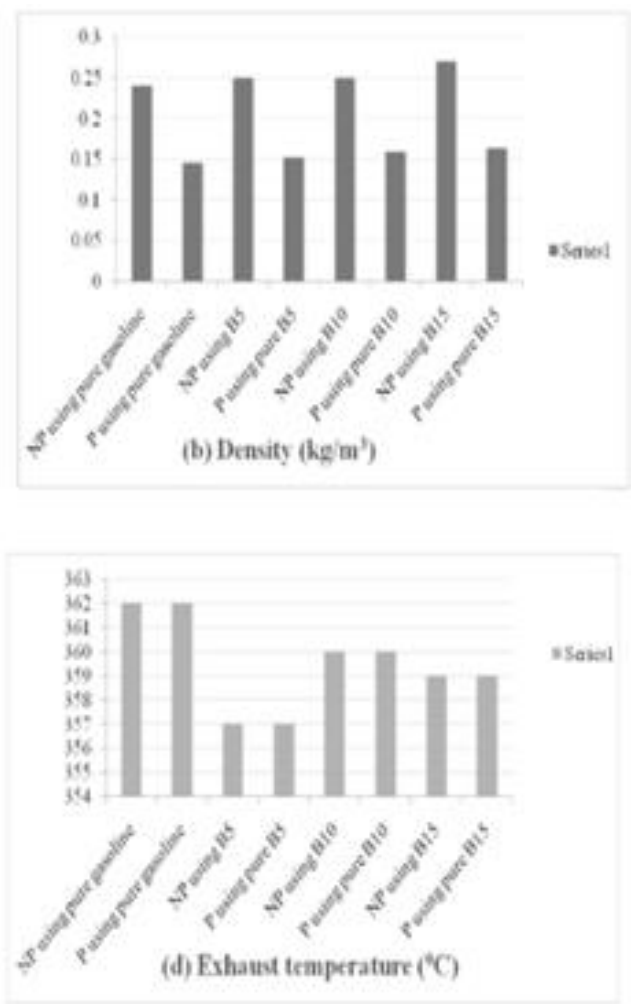

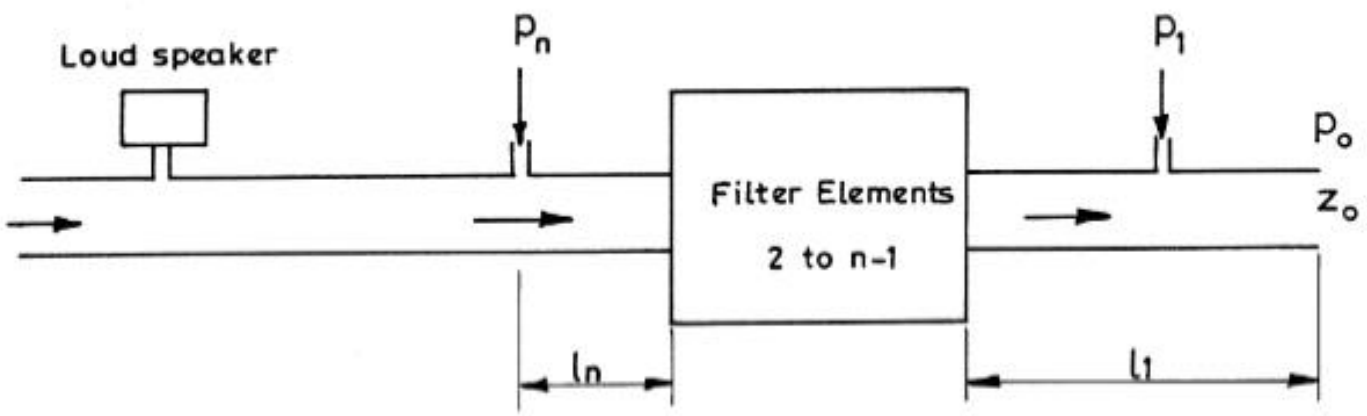

Fig. 2. Measurement of noise reduction [4]

typically small mean flow Mach numbers. The result shows clear effect of mean flow on TL of the side inlet/ outlet chambers has been studied.

S. Allam et al. studied acoustic plane wave properties of a complex geometry, and some parameter were experimentally calculated such as reflection coefficient using the TMM on the upstream and downstream side of the test object. In this research Presented and tested a method for measuring the twoport data in the form of a scattering-matrix, describing the relationship between the traveling wave amplitudes of the pressure on either side of the test object. 


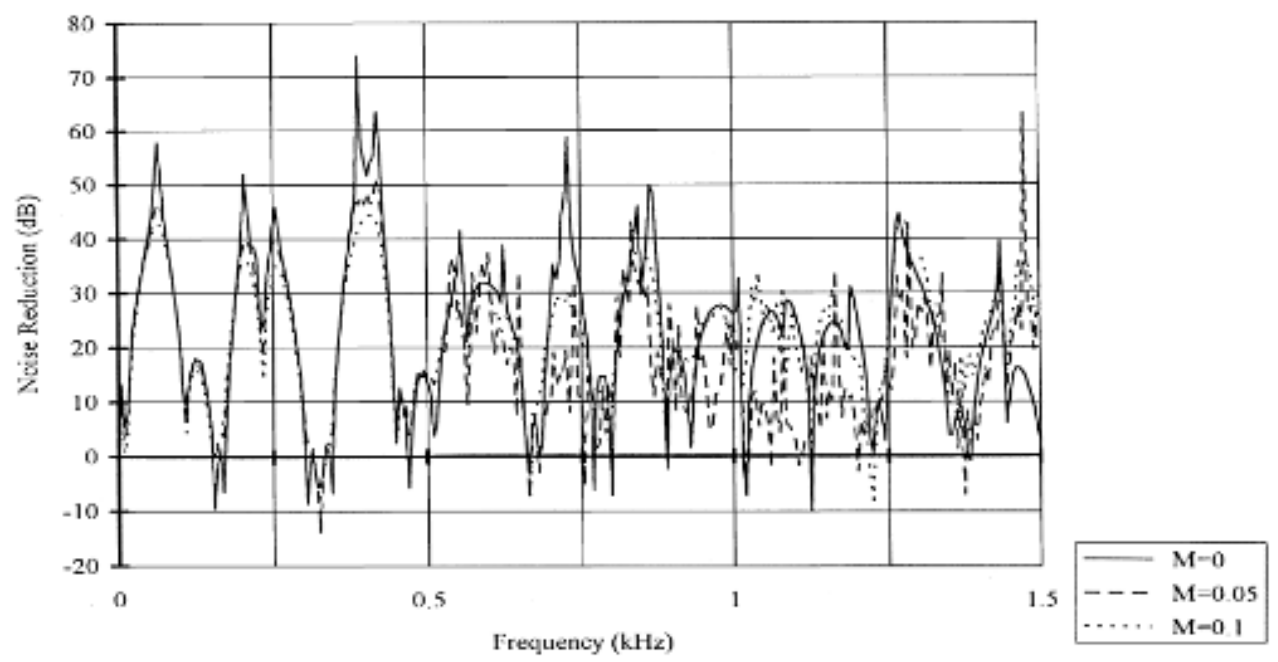

Fig. 3. The effects of different Mach number on noise reduction [5]

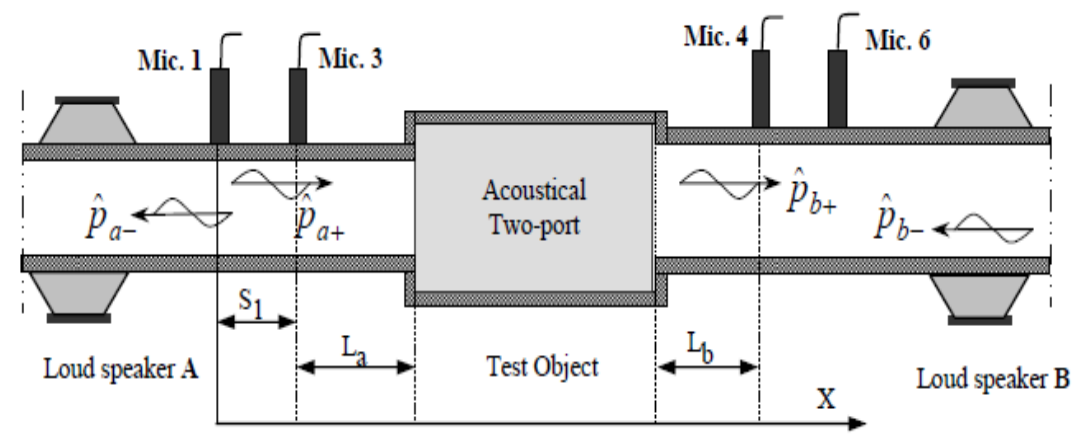

Fig. 4. Acoustical Two-Part method for a muffler [6]

Linear and passive two-port in the frequency domain, be written:

$$
X=T Y,
$$

where, $X / Y$ are the state vectors at the input/output and $T$ is a [2×2]-matrix, which is independent of $Y$. To determine $T$, from measurements four unknown must be determined.

The transfer-matrix form uses the acoustic pressure $P$ and the volume velocity $\mathrm{V}$.

$X=[P a, V a]$ and $Y=[P b, V b]$ here $[\mathrm{a}]$ and $[\mathrm{b}]$ represent two different ducts cross section. The transfer-matrix could be written in the following form:

$$
\begin{gathered}
{\left[\begin{array}{c}
P_{a} \\
V_{a}
\end{array}\right]=\left[\begin{array}{ll}
T_{a a} & T_{a b} \\
T_{b a} & T_{b b}
\end{array}\right]\left[\begin{array}{c}
P_{b} \\
V_{b}
\end{array}\right],} \\
P_{a}=P_{+} \exp \left(-i k^{a} L_{a}\right)+P_{-} \exp \left(i k^{a} L_{a}\right), \\
V_{a}=\frac{A_{a}}{\rho c}\left\{\left(P_{+} \exp \left(-i k^{a} L_{a}\right)-P_{-} \exp \left(i k^{a} L_{a}\right)\right\},\right. \\
P_{b}=P_{+} \exp \left(-i k^{b} L_{b}\right)+P_{-} \exp \left(i k^{b} L_{b}\right), \\
V_{b}=\frac{A_{b}}{\rho c}\left\{\left(P_{+} \exp \left(-i k^{b} L_{b}\right)-P_{-} \exp \left(i k^{b} L_{b}\right)\right\},\right.
\end{gathered}
$$

The result shows, the acoustic two port, of a single diaphragm orifice and then validated with the theoretical result has been calculated using 3D FEM software FEMLAB from other literatures. ElSharkawy and El-Chazly they present a critical survey of latest technique to determine the transmission loss, reflection coefficient and attenuation of sound in regarding the basic theories used for muffler design and analysis. The exact and approximate methods for solution are reviewed as well. The Actual measurements of sound pressure levels in the exhaust pipes of large engines showed that the maximum levels are in the order of $165 \mathrm{~dB}$ at $300 \mathrm{~Hz}$ and about $135 \mathrm{~dB}$ at $1000 \mathrm{~Hz}$. The non-linear effects play an important role in the attenuation of sound. The nonlinear effect scan be classified into two types: the nonlinearity of the gas itself which is significant only at sound pressure levels exceeding $160 \mathrm{~dB}$, and the material non-linearity (especially perforated plates) which may be significant at pressure levels above $30 \mathrm{~dB}$.

Sathyanarayana and Munjal predicting radiated noise requires a model of the acoustic behavior of the intake/exhaust system and a model of the engine cycle source characteristics. In their research the frequency domain analysis of mufflers is done by means of the transfer matrix method. The result shows the effect of 
duct length and expansion chamber on muffler performance and transmission loss. Desmons and Kergomard studied the noise radiated from the exhaust system of a four-cylinder engine, analytically and numerically, and validated to experiment. The calculation includes the effect of the exact shape of the volume velocity signal produced by a cylinder during opening two valves. The pertinence of the resonances of the whole system including exhaust and manifold is demonstrated. The results show the overlap duration plays a key role in the amplitude of the harmonics. Heymann present a research paper consist of two part. The first part reviews, in non-mathematical terms, the analysis techniques which can be used for acoustic circuits. Slightly more mathematical appendices were used to express the acoustic impedance and acoustic velocity in fluid-filled ducts. The second part was deal more directly with practical considerations in the design of acoustic test loops for liquid piping system components, and important property of a noise source is the distribution of acoustic pressures over the crosssection, since this will determine to what degree the various modes of propagation will be excited.

In another technical paper of Heymann studied the measurements and characterization of the acoustic
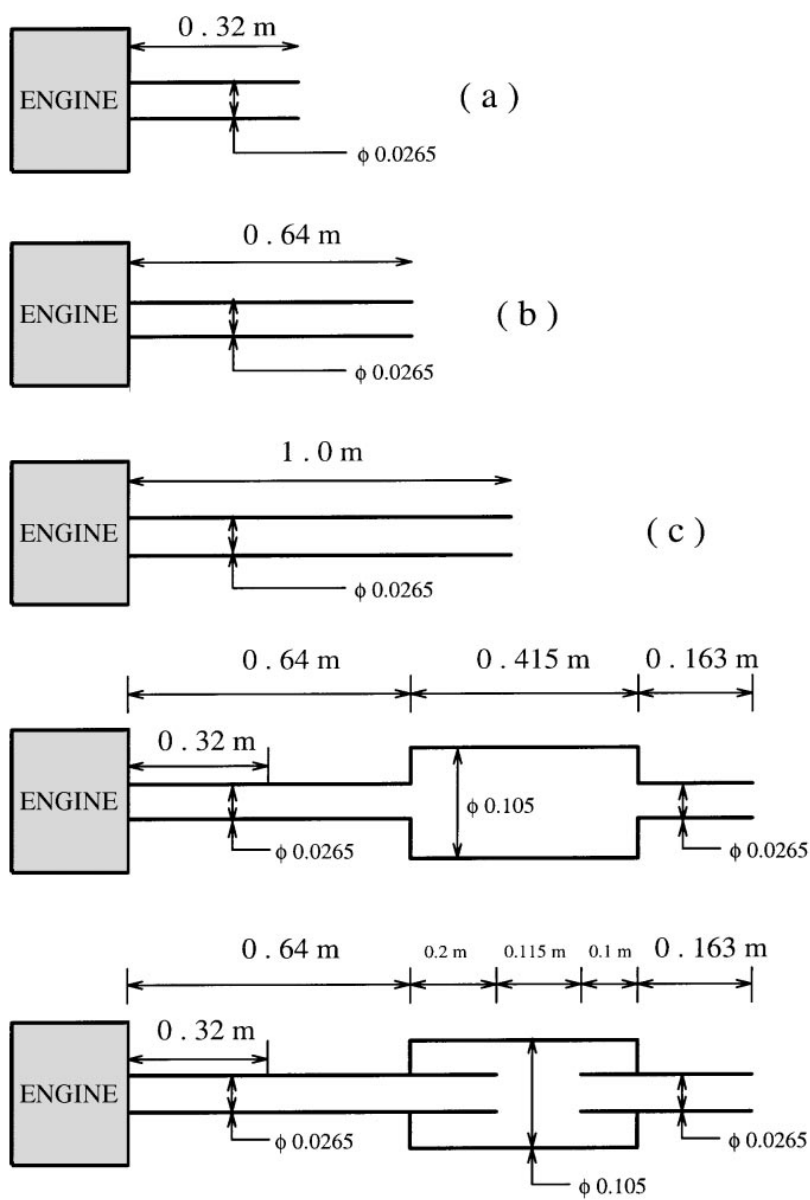

Fig. 5. The various muffler configurations investigated [8] (c)

performance of fluid system components, for ducts and acoustic filters. The first part reviewed, in nonmathematical terms, the analysis techniques which can be used for acoustic circuits and pointed out that the effect of any component cannot be predicted accurately without making a complete circuit analysis. Approaches toward acoustic characterization of noise sources were discussed. Second part deals more directly with practical considerations in the design of acoustic test loops for duct system components.

H. Bailliet et al. studied multi-modal acoustic propagation in circular duct with turbulent flow. An acoustic source has been especially designed to generate high level acoustic power. the basic design a laboratory facility that share common acoustic and mean flow features with real engines. Apart from classical aerodynamic study, a Laser Doppler Velocimetry (LDV) has been adapted to the purpose f measuring acoustic velocity in a turbulent mean ow either by using techniques developed in the xt of fluid mechanics measurement or by using east mean square detection in which turbulence is viewed as a noise. 
Flow profiles have been performed for different locations in the duct and at different Mach numbers from 0.1 to 0.3 . The axial velocity was measured across the section with a $0.1 \mathrm{~mm}$ step near the wall and with gradually growing steps up to $5 \mathrm{~mm}$ in the center of the duct. These results show that LDV is an appropriate method for estimating acoustic velocity with a mean flow. An experiment was conducted by Fenech and Ganz to measure the characteristics of flow noise in a bounded system with forced circulation. The flow noise facility is described in research paper with location of vortex shedding in the conducting rectangular ducting was describe. The experimental was done by the insertion of cylinders of various diameters and pitch perpendicular to the flow. The flow noise experiment provides many information about the nature of the acoustical noise in the test section and about the response of the cover plate to flow noise excitation. The pressure fluctuations spectrum results, it is seen that, at low flow velocities, the acoustical noise in the cavity consists mainly of blower noise peaks at the blade passage frequency with some lower broad band noise due to air turbulence. The flow dynamic head is considered the most important parameter in flow noise production, Furthermore, the Reynolds number, which is a measure of turbulence in the flow, is also of significance in relating flow noise level, flow velocity and conduit size.

Bilawchuk and Fyfe used a proper examines of three different methods used in calculation of TL values; SYSNOISE is an FEM/BEM based computational acoustics program, the 4-pole transfer matrix method with the 3-point method and (traditional) laboratory method. To set up this experimental facility, a high-level acoustic source was developed to generate higher propagating modes in the presence of mean flow. A comparison of these methods based on

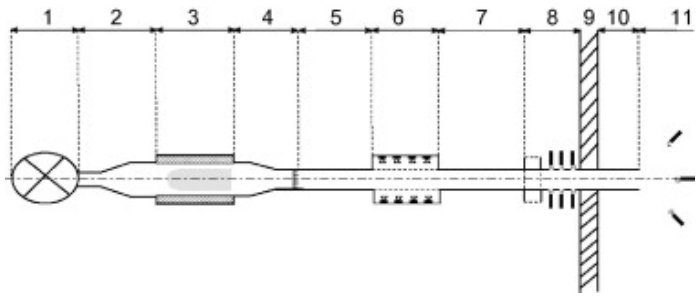

Fig. 6. Experimental apparatus [12]

such criteria as accuracy in terms of computation time. The result predicts the performance of a silencer system, acoustic propagation inside a cylindrical duct in presence of a turbulent mean flow. It can be seen the results for both the traditional and 3-point methods overlay each other exactly. The 4-pole FEM results match those of the other methods, and the 4-pole BEM results are also very close to the other BEM results.
F. Payri et al. presented in their research paper exact solution using linear acoustic theory and nonlinear calculations. the pressure and mass velocity distributions along the exhaust system were used to evaluate the results from linear acoustic theory. The mass velocity distribution presents the additional interest that it may be related to the insertion loss of the system.

A full non-linear model was used to estimate the pressure and mass velocity distributions along the exhaust line. The model was validated by comparison with experiments at selected points in the exhaust system. Bies and Hansen studied flow resistance information for the calculation of the acoustical properties of porous materials. Some definition and expression has been done on non-linear flow resistance. Experimental investigation has shown that, for a wide range of materials the differential pressure, and the induced normal velocity, of the gas at the surface of the material are linearly related provided that the normal velocity is small.

Yasser Elnemr investigate and performed on three of the most nowadays commonly used absorbing materials in exhaust systems (PowerTex, Biosil, and HakoTherm), with perforated through flow chamber silencers, and a perforated multi chamber silencers the aim was to show the influence of adding the absorbing material on these silencers acoustic resonances. The simulation part was there using FEM approaches; COMSOL MULTIPHYSICS as a finite element tool analyzing the problems in 3-D, as shown in Figure 7 AVL BOOST-SID as a 1-D tool, and show a perfect match with the measurement results, so both of them can be used in the design phase of the commercial mufflers.

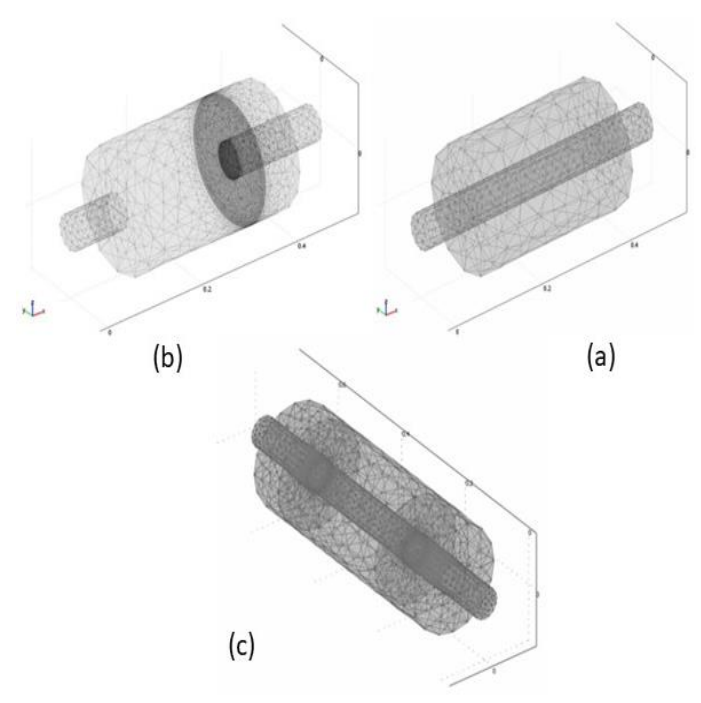

Fig. 7. Fig. 7. (a) Finite element model for the long chamber of muffler, (b) Finite element model for the two chambers muffler, (c) Finite element model for the three chambers muffler [17] 
Part of simulation done by 1D AVL-Boost. The model consists of system boundary, ducts, and junctions. Linear acoustic calculation was done to the muffler to verify the performance, measure transmission loss and noise reduction. As shown in Figure 8. B. Mohamad et al. Used 1D AVL-Boost software to describe the effect of using different kind blend fuels on engine performance and exhaust properties. The result show variation of outlet temperature, and emission gas characteristics for $\mathrm{CO}$, $\mathrm{NOx}$, and $\mathrm{CO}_{2}$ by using different volume percentage of alcohol-gasoline blends. B. Mohamad et al. studied the effect of Ethanol-Gasoline blend fuel on engine power output and emissions, the literatures results shows great improvement in combustion process and exhaust gas characteristics. B. Mohamad et al. Presented in their technical paper review of muffler used in industry, and this review depicts flow and temperature distribution along the muffler ducts. The techniques for different methods used in the design, calculation and construction of muffler both experimentally, practically and transmission loss characteristics were described. 1D calculations are much faster, and still give a good overview of the system under investigation.

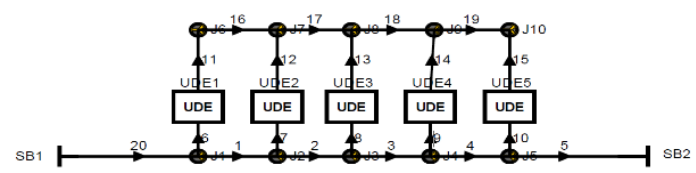

Fig. 8. AVL BOOST-SID Model for the long chamber configuration of muffler, with no absorbing material

Bies and Hansen describe and analyse the flow resistance in muffler consist of porous material: homogeneous fibrous and open cell foamed products, to improve the transmission loss through pipe wrappings and enclosure walls and the attenuation of sound propagating in ducts. Nakra et al. Experimental work was carried out on the design and analysing performance of the reactive type of muffler, fitted on internal combustion engines to reduce the exhaust noise, the relationships used were those derived from plane wave or acoustic filter theory. Experimentally it has been reported that the mean back pressure of the exhaust system is an important parameter so far as engine performance is concerned. The absorption material was recommended to reduce a noise level at diesel combustion high frequency. Overall sound pressure level was $108 \mathrm{db}$ without muffler, with muffler was $97 \mathrm{db}$, and with resonator muffler was $101 \mathrm{dp}$.

Lamancusa studied The transmission loss of a double expansion chamber muffler with unequal chambers has been derived and used to study the performance It is also shown that significant tuning benefits result with chambers of unequal size.

Howard and Richard describe the acoustic performance of mufflers that include, Transmission Loss (TL), and Noise Reduction (NR). Numerical predictions of the expected transmission loss of a quarter-wave tube were made using Finite Element Analysis (FEA). One benefit of using FEA is that the transmission loss can be predicted for the three sidebranch geometries considered here.as show in Figure 9.

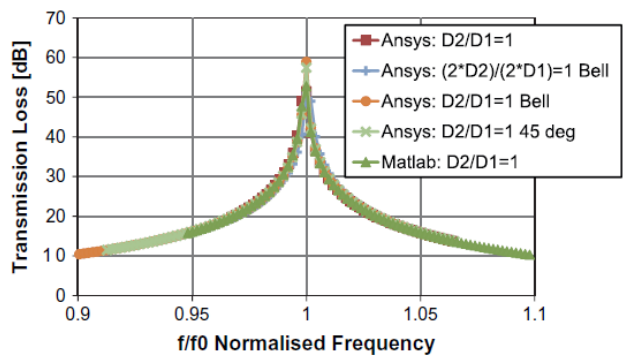

Fig. 9. Theoretical predictions of transmission loss of a quarter-wave tube using different solver [24]

Experimental testing was conducted using three configurations of side-branch geometries with an adaptive quarter-wave tube attached to the exhaust of a large diesel engine. It was shown that the sidebranch with the bell-mouth opening provided the greatest noise reduction and hence was the least affected by the gas flow.

Singh and Rubini studied experimentally and numerically the simple expansion muffler both with and without flow are obtained to compare attenuation in forced pulsation for various mean-flow velocities. A three-dimensional Large Eddy Simulation was carried out on the same muffler geometry to ensure good agreement for detailed analysis of the muffler. See Figure 10.

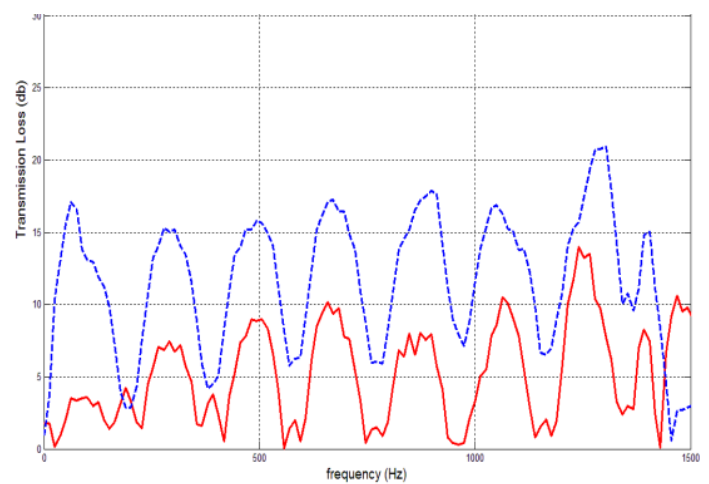

Fig. 10. Comparison of FFT of muffler without any flow and muffler at $10 \mathrm{~m} / \mathrm{s}$ flow for generator frequency of $1500 \mathrm{~Hz}$ [25] 
As shown in Figure 10. A mean flow of $10 \mathrm{~m} / \mathrm{s}$ (Mach number of 0.03) was considered. Using Unsteady Reynolds Averaged Navier-Stokes (URANS) simulation of a muffler conducted.

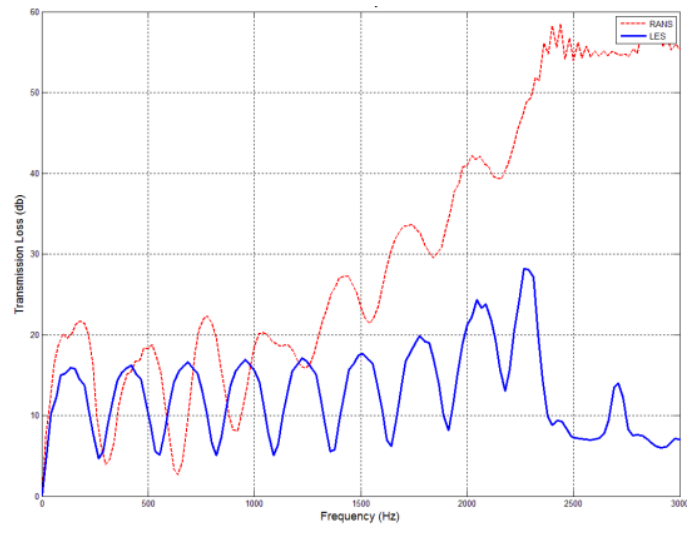

Fig. 11. Comparison of transmission loss spectrum for RANS and LES in simple expansion muffler [25]

The results are presented to demonstrate inherent limitations associated with this approach, and validated for compressible Large Eddy Simulation (LES) of channel flow. The result show improvement in the prediction of vortex shedding inside the chamber is highlighted in comparison to the URANS method. Further, the effect of forced pulsation on flow-acoustic is observed. Munjal present different approaches for measurement and evaluation of the source characteristics of an engine exhaust system have been briefly reviewed, with particular emphasis on their relative implications and limitations. These approaches combine the advantages of the frequencydomain analysis of mufflers with those of the timedomain analysis of the exhaust manifold source. Because in some method does not require prior knowledge of the source characteristics, like piston motion, exhaust valve/port opening and high blowdown pressure in the cylinder.

\section{CONCLUSIONS}

The acoustic performances of proposed muffler were studied experimentally and theoretically in the present review paper. The simulation models for flow and regeneration in internal combustion engine. The models have been implemented into the 1D code BOOST and into the 3D code FIRE and other CFD codes. A workflow is designed which makes it possible to automatically determine the necessary model parameters and to use them in both $1 \mathrm{D}$ and 3D simulations. It was concluded that studying on noise eliminations by computational fluid dynamic and in experimental approach becomes a new area of study.

\section{References}

1. Prakash Chandra Mishra, Sourav Kumar Kar, Harshit Mishra, and Anand Gupta. (2016). Modeling for combined effect of muffler geometry modification and blended fuel use on exhaust performance of a four-stroke engine: A computational fluid dynamics approach. Applied Thermal Engineering (108)1105-1118.

2. K. Ashok Reddy. (2018). A Critical Review on Acoustic Methods \& Materials of a Muffler. Materials Today: Proceedings (4)7313-7334, 2017.

3. Prakash Chandra Mishra, Sourav Kumar Kar, and Harshit Mishra. Effect of perforation on exhaust performance of a turbo pipe type muffler using methanol and gasoline blended fuel: A step to NOx control. Journal of Cleaner Production (183)869-879.

4. M.L. Munjal, B.K. Behera, P.T. Thawani. (1998). Transfer Matrix Model for the Reverse-flow, three-duct, Open End Perforated Element Muffler. Applied Acoustics, 54(3)229-238.

5. M.L. Munjal. (1997). Plane wave analysis of side inlet/outlet chamber mufflers with mean flow. Applied Acoustics, 52(2), 165-175.

6. S. Allam, H. Bodén, and M. Åbom. (2006). Overdetermination in acoustic two-port data Measurement. The thirteenth International congress on sound and vibration, Vienna-Austria.

7. A.I. El-Sharkawy and N.M. El-Chazly. (1987). A critical survey of basic theories used in muffler design and analysis. Applied Acoustics, 20(3), 195-218.

8. Y. Sathyanarayana, M.L. Munjal. (2000). A hybrid approach for aeroacoustic analysis of the engine exhaust system", Applied Acoustics, 60(4), 425-450.

9. L. Desmons, J. Kergomard. (1994). Simple analysis of exhaust noise produced by a four cylinder engine. Applied Acoustics, 41(2), 127-155.

10. F.J. Heymann. (1971). Acoustic performance tests and parameters for fluid piping system components: A critical evaluation of the state of the art: Part 1. Applied Acoustics, 4(2), 79-101.

11. F.J. Heymann. (1971). Acoustic performance tests and parameters for fluid piping system components: A critical evaluation of the state of the art: Part 2. Applied Acoustics, 49(3), 155-173.

12. H. Bailliet, R. Boucheron, J.-P. Dalmont, Ph. Herzog, S. Moreau and J.-C. Valière. (2012). Setting up an experimental apparatus for the study of multimodal acoustic propagation with turbulent mean flow. Applied Acoustics, 73(3), 191-197.

13. Henri Fenech, I. Ganz. (1986). Acoustic excitation of a square plate by turbulent flow noise. Applied Acoustics, 19(3), 167-182.

14. S. Bilawchuk, K.R. Fyfe. (2003). Comparison and implementation of the various numerical methods used for calculating transmission loss in silencer systems. Applied Acoustics, 64(9), 903-916.

15. F. Payri, A.J. Torregrosa, and R. Payri. (2000). Evaluation through pressure and mass velocity distributions of the linear acoustical description of I. C. engine exhaust systems. Applied Acoustics, 60(4), 489504.

16. D.A. Bies, C.H. Hansen. (1980). Flow resistance information for acoustical design. Applied Acoustics, 13(3), 357-391.

17. Yasser Elnemr. (2007). Investigation of the acoustic Performance of dissipative mufflers: Influence of different absorbing materials and packing densities. Virtual Vehicle Conference, Graz-Austria.

18. B. Mohamad, G. Szepesi \& B. Bolló. (2017). Combustion Optimization in Spark Ignition Engines. 
Multi-Science - XXXI. microCAD Scientific Conference. University of Miskolc-Hungary.

19. B. Mohamad, G. Szepesi \& B. Bolló. (2018). Review Article: Effect of Ethanol-Gasoline Fuel Blends on the Exhaust Emissions and Characteristics of SI Engines. Lecture Notes in Mechanical Engineering. 29-41.

20. B. Mohamad, G. Szepesi \& B. Bolló. (2017). Review Article: Modelling and Analysis of a Gasoline Engine Exhaust Gas Systems. International Scientific Conference on Advances in Mechanical Engineering. University of Debrecen-Hungary.

21. D. A. Bies \& C. H. Hansen. (1980). Flow Resistance Information for Acoustical Design. Applied Acoustics 13, 357-391.

22. B. C. Nakra, W, K. Sa'id, \& A. Nassir. (1981). Investigations on Mufflers for Internal Combustion Engines. Applied Acoustics 14, 135145.

23. J S Lamancusa. (1988). The Transmission Loss of Double Expansion Chamber Mufflers with Unequal Size Chambers. Applied Acoustics 24, 15-32.

24. Carl Q. Howard \& Richard A. Craig. (2014). Noise reduction using a quarter wave tube with different orifice geometries. Applied Acoustics 76, 180-186.

25. N. K. Singh \& P. A. Rubini. (2015). Large Eddy Simulation of acoustic pulse propagation and turbulent flow interaction in expansion mufflers. Applied Acoustics, 98 pp.6-19.

26. M. L. Munjal. (2004). Acoustic Characterization of an Engine Exhaust Source - A Review. Proceedings of Acoustics.

\section{Biographical note}

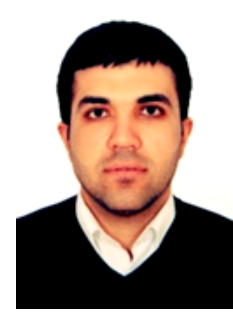

Barhm Mohamad received his M.E. degree in Mechanical Engineering in 2012 and start his Ph.D studies in 2016 in Faculty of Mechanical Engineering and Informatics University of MiskolcHungary. respectively. Since 2018 he has been a technical researcher in the Formula Student-Miskolc at the University of Miskolc, His scientific interests focus on problems concerning intake and exhaust systems in modern automotives and diagnostics. He has participated in 2 international and 3 national research projects, presenting results of his work at 5 international and 2 national conferences, published more than 9 scientific papers in international and national journals, book chapters, as well as conference proceedings. 